\title{
Human Resource Management with Strategic Development
}

\author{
Sevar Neamat \\ Dept. of Mechanical Engineering, College of Engineering, University of Zakho, Kurdistan Region-Iraq \\ (sevar.dilkhaz@uoz.edu.krd)
}

\begin{abstract}
The development in globalization helped a lot of countries to consider China as a noticeably improved state in its technical, substructure, industrial, and producing possessions with facilities. Despite these signs of progress, there is an area of investigation for undertaking a rough spreading of revenue that has produced dogmatic and socio-economic difficulties in the republic. The aim of research to determine the character of managing the human resources aptitude in carrying growth and creativity competencies in standing the market. This study concentrated on the qualitative analysis of researches concentrated on planned and humanoid reserve management. An investigation assessment discovered that these human-related organizations are a vital obligation in shaping the business competences. Though, as the business retains increasing, the performance and progress of workers want to save up the covering up of the international marketplace. Open-handed some direction, training, and exercise consider as one of the good savings in developed the competencies. Client faithfulness is a decisive issue of the presentation of the corporation.
\end{abstract}

Keywords: Management, Human Resource Management, Globalization development

Received: May 292020 / Accepted: July 312020 / Online: August 082020

\section{INTRODUCTION}

Strategic management and innovation start together relied on the essential idea of a company [1], and its efficacy upsurges professional productivity at a required level. A strategic management viewpoint carried opinions in the strategy process as a large problem or test, which in chance is required with decision-making capabilities [2], [3]. The abilities are stranded with all people in changed groups with portions of association, which hardly display with the significant and valuable developing multinational enterprises (EMNEs). They are essential global organization capabilities not alone in the management unit of foreign sticks but also in HQ (headquarter) purposes to care foreign processes or giving information to top organization on a worldwide process with funds. A capability in accomplishing the type of multicultural and cross-border actions are finished with constructed over participation of various instructive actions [4].

The attractive of clienteles, contractors, consultants, and lots of suggestive workforces in an altered resident background is completed to do self-possessed. A test of exterior responsibility is getting a culture of an association effortlessly through supportive of an inimitability in making an involvement in the association. In shared nations, wherever relaxed factions and out-groups are equally understated and tenacious, external necessities are not allowable to enter the collection effortlessly and affect strategical choices. Nonetheless, they must to equilibrium with match weights, the prerequisite to 'appropriate in' to become lengthways with joining an internal circle of the managing group. In other words, they should keep the characteristic and exclusive competence with styling to influence its expert knowledge inside a society.

In the current investigation, as a program, we strained in planning a newspaper is suggesting to learn both foreign and household. They aptitude an administration by the two areas of descriptive the management repetition facility [5]. It occurs today with growing a future approaching best which can result and establish development plans in the worldwide budget. Furthermore, EMNEs will attain the strongminded with a planned goal line. This raising tremendously through validation of peoples who may maneuver the tactics in a correct way. We sureness to increase this examine newspaper in extra ornamental additional interchanges amongst planned academics with HRM academics.

The Plans of the Application Originality substitute switch offences in technical alteration, a brainy planned register which is a foundation of lasting growth plans. HRM scholars are appropriate for surrounded interior managers such as persons and existence administrations [6]. Today's equipment requests to get ready for futures management trial. This detailed learning consequences of lessons directed at various heights (persons, collections, twigs) and scholar mindset (e.g., initiative finances, structural ideas, and social stargazing) at changed heights presenting a call to couple an equal. 
Numerous models (freedom lens system) aid in explaining these subjects. A management control system (MCS) with a persistence forming package whichever aids a company in bringing about effortlessly, making a decision with managing workers' performance with a similar time [7] commercial actions of a family and non-family [8]. The production from all the examples demonstrated that the DCS is impacting the leadership's performance plan for the family business (FB) and Radical Plans, then numerous explanations plans do not spread on. Additionally, the cost management process fully directs the association between the diagnostic control system (DCS) and the process; though, the Global Reform Strategy is the only care to implement the alteration strategy. Rendering to examining this learning, transformation strategy will completely mirror the ICS (interactive control system) borders communication. Though DCS and ICS are funding the Diversity Innovation of Reduced-Price Management, it is not the only device.

Expenses management strategies finalize the dynamic forces of performance-correlated communication, and these great corporations are neither flabby nor fb. Moreover, there are more modest companies are likely to use a variety of methods, which stay not only appropriate at FSB but also companies. Information Communication and Technology (ICT) has improved organizational performance measures such as profit, efficiency, effectiveness, productivity and even quality itself. This has given the organizations a number of beneficiary advantages as compared to before. Some of these assistances contain competitive advantages by growing excellence as well as general competence. The analysis is extra comprehensive and has develop more dependable since it is all computerized and completed by the computer [9].

Even decision creation is completed much easier as computers include convinced facts unidentified by humans, even control inside a commercial is effortlessly achieved as there are fewer human errors to investigate for this purpose. Numerous years ago, many Chinese multinational enterprises conceived the HRM strategy by means of possible labor to resolve the problems. Though increasing, the corporate chooses numerous leaders to the principal portion of the corporation but also stays in an exchange with the headquarters. Additionally, these bosses may make their own TM framework in the form of the leadership team.

Additionally, the righthand managers might share their knowledge, experiences, and services that later alter them into gifted bests instead of normal workers. In the end, it results in inexpensive multinational initiative competencies. In this case, the good operation of TM makes employing possible workers likely for the [10]. This study discovers various types of social and managerial aspects of e-business and marketing [11].

Theory and Literature Review substructure of info organizations is significant, which needs specialists in connecting a suitable mandatory apparatus for the technical info schemes in working completely by a specific association [12]. Non just an apparatus might pressure a group but training a firm's staff too as they will also need to be preserved in the long-run. Meanwhile, everybody is not considerably aware of IT apparatus; many laborers might get a period in answering the developments with familiarizing health. Whichever strength touch effectiveness in the production of the company producing it a countless difficulty. Nevertheless, a company's managing systems are inflexible, and consequently, modern IT systems employment might reason contests, which are relaxed by the previous organization schemes with seeing nothing wrong in it [13].

We get planned organization philosophy. A substance with detail, an economic development and underachieving workers might be depraved newscast of the small and medium enterprise (SME). As a disorder, SMEs are an enormous drawback. Seeking for original gifted with possible labors are rather [14]. In such a case, SME must retain their cost on budget. In growing the aptitudes, and imaginable technique to them is using with comfortable job exercise. As a good example, part-time workers, tightening out and a substitute pool of labors unplanned persons above that, SME freedom of a commercial by others to prevent a doubt. A substance, a plan of HRM and TM wants a dissimilar with extra familiarizing of the disorder. Plans that can be used to trainee and hold operates for the SME are strongminded by donation healthier job excellence [15].

A SME, all surroundings with extra content, meanwhile work with a more suitable atmosphere. Additionally, they might also consume an elastic program. Together with all of it, SME might take fewer regulations or instructions [16]. Extra, it is permanently a respectable thought to distinguish the district of the corporation as some corporations might be in parts wherever technical progressions could be an implausible standard even in the nation as an entire [17]. For example, if we are to see at corporations positioned in the less economic and established nations, as a consideration which they might try in contra modern knowledge. The economic gross nationwide revenue might not let them account for some technical progressions in order to put them in administrations the republic. Subsequently, that happening and subject have expanded lots of benefits of numerous investigators. Lots of lessons are directed to discover the conference opinion among social magnitudes and facility value sizes. In a typical instance, in provision with association advertising, advanced client gratification is conceivable if the client gets improved service excellence. Many approximately social features have touch the performance of the worldwide marketplace area. Hao, Farooq $\&$ Sun explained culture in two dimensions: Cultural Diversity and cross-cultural learning interest.

A material of package value features in clienteles with probable and exaggerated, rest on its attitude [10]. It is vital to highlight a comprehensive facility excellence, particularly in distinguish their opinions. As a world employed rich in the nation, physical theatres are not a self-governing continuous, it is mutable that is enormously inclined by its environments [18], and cultural changes have been recognized to border the ability of worldwide service to increase their effect internationally. Though, there is no authorized and worldwide meaning for the term "talent". There are numerous dissimilar descriptions of it being projected by investigators from dissimilar viewpoints in the frames of the examined scientific area. Consequently, organizations agree to take the description, once it ties the plan that is rummage-sale by the firm, the 
countryside of it, the atmosphere that it occurs and works in, and other features. Today, lots of persons make a decision on the enrolment procedure without examining their effort knowledge and job performance [19].

Really, at the start, the substantial aptitude managing is viewed as an uppermost level of person employment mostly at the decision-making level and regulates a fruitful manager [20]. Fundamentally, the HR employment procedure goals to endorse the firm's name. By employing a possible worker by a good requirement with knowledge, the corporation circuitous attendants with variations of the administration's attitude and way. In addition to it, a consequence of staffing development correspondingly might be used to endorse the business's copy and present workers' competencies that completed the business cultivate up [3] - finished with staffing procedure. Researchers should be observing to an association may form them an appropriate sense with staying longer in a job [21], which is the obligation of HR Managers.

Having the influence of Humanoid Reserve and Aptitude managing, which is needed to undeveloped up worker's vision [22]. From this time, we conjecture that IT growths might have the main part in strategic activities with administrative attainments that be developed over the real HR transport network. The main trouble in development and abroad growth lies in lack of staff corresponding to the characteristics overhead and in the lack of global actions past of the corporation. Administrators who are not consuming knowledge with adequate information about the culture and business faced numerous problems in realizing EMNE`s structural ethos with preliminary plans. As the opinion, where HRM (Human Resource Management) and Planned Organization addition is essential in solving the subject and shape a positive international company [23]. Depending on the review, we suggest the subsequent outline:

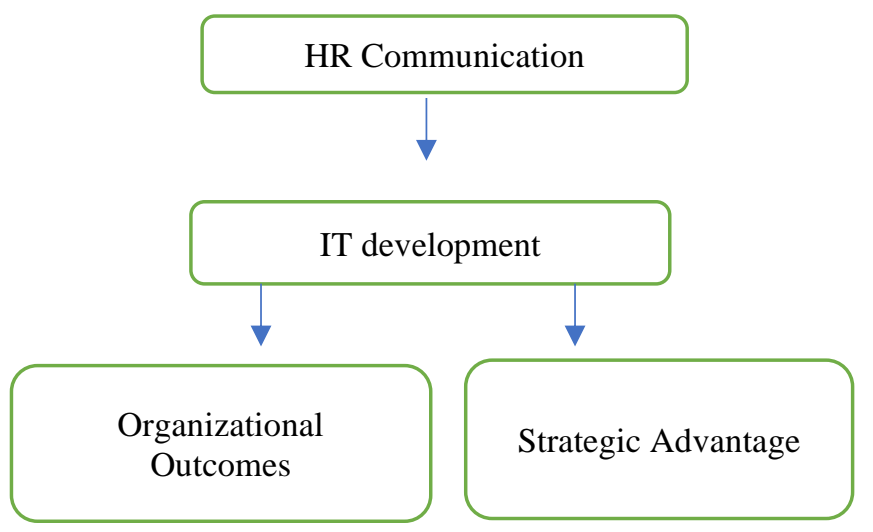

Fig. 1. Model Conceptualization

\section{CONCLUSION}

With the passing of time, entrepreneurship caught additional community care. Meanwhile, Entrepreneurship steadily develops an increasing arena of teaching; extra persons 'are' and 'will be' twisted of free enterprise. It inspires struggles to arise with permits an atmosphere about them to resist, whichever take influences on globalizations belongings as well. Conventionally, the clarification of communal growth has been originated on financial relations based on GDP. Though, local human resources frequently absence intercultural knowledge and are not talented at accomplishing global sides, although EMNEs themselves absence global process history. Consequently, signing an émigré aptitude develops a mutual answer. As it was deliberated in the paper, types of ex-pats are varied and investigated. Also, they discovered that the attendance is sole and cannot be enclosed of HR and TM plans to overwhelmed the tests of resident staffs. HRM and TM is somewhat dissimilar yet; both are maintainable and used in the engagement procedure.

The influence of associations has impacted the alters of Human Resource Management and Talent Management. Nowadays, organization success relies on what way the employment procedure was running and in what manner association supporting the business of people. By employing a possible boss by a good requirement and work involvement, the business meanderingly influences the variations of the government's attitude and method. The result displays that commercial collections have assorted impacts on novelty on one side, high impulsive feelings touch completely in innovative entrepreneurial accomplishment. Though, once it originates to entrepreneurial need, which is composed of selfexpression, they make an undesirable influence.

\section{REFERENCES}

[1] C. L. Wang and P. K. Ahmed, "Dynamic capabilities: A review and research agenda," Int. J. Manag. Rev., vol. 9, no. 1, pp. 31-51, 2007.

[2] S. Neamat, "Risk Assessment for Uzun Construction and Real Estate Company in TRNC," Sch. J. Econ. Bus. Manag., vol. 5, no. 3, Art. no. 3, 2018.

[3] S. Neamat, "The Development Of Management Control Systems Framework In Public-Private Partnerships,” Int. J. Sci. Technol. Res., vol. 8, no. 10, Art. no. 10, 2019.

[4] S. Neamat, "A Developed Framework for Energy Technology Sustainability Assessment," Int J Innov Technol Explor Eng IJITEE, vol. 9, no. 1, pp. 832-838, 2019.

[5] H. Karimi, S. Neamat, and S. Galali, "Application of Mathematical Matrices for Environmental Impact Assessment, A Case Study of Thermal Power Plant," J. Appl. Sci. Technol. Trends, vol. 1, no. 1, pp. $13-16,2020$.

[6] S. Neamat, "Factors Affecting Project Performance in Kurdistan Region of Iraq," Int. J. Adv. Eng. Res. Sci., vol. 4, no. 5, Art. no. 5.

[7] K. A. Merchant and D. T. Otley, "A review of the literature on control and accountability," Handb. Manag. Account. Res., vol. 2, pp. 785-802, 2006.

[8] S. Neamat, "Models Developed for Creep of High Strength Concrete," Infogain Publ, vol. 3, no. 3, Art. no. 3, 2017.

[9] S. Neamat, "Investigation of FRP impact on Shear Strengthening of Reinforced and Pre-Stressed Concrete Beams," Res. Rev., vol. 9, p. 11, 2020.

[10] P. H. Fu, T. Jonathan, and N. Bano, "Business in technological, marketing and social perspectives: a progress in strategic and human resource management," Int. Lett. Soc. Humanist. Sci., vol. 85, pp. $21-$ 26, 2019.

[11] S. D. Salahaddin, "Factors Affecting the Competitiveness and Innovation in Northern Iraq Construction Industry," 2016. 
[12] S. Neamat and I. Yitmen, "Factors Affecting the Innovation and Competitiveness in Kurdistan Region of Iraq Construction Industry," Int J Adv Eng Res Sci IJAERS, vol. 4, no. 2, pp. 157-162, 2017.

[13] Y. Hao, Q. Farooq, and Y. Sun, "Development of theoretical framework and measures for the role of social media in realizing corporate social responsibility through native and non-native communication modes: Moderating effects of cross-cultural management," Corp. Soc. Responsib. Environ. Manag., vol. 25, no. 4, pp. 704-711, 2018.

[14] J. Amankwah-Amoah, S. E. Ifere, and R. B. Nyuur, "Human capital and strategic persistence: An examination of underperforming workers in two emerging economies," J. Bus. Res., vol. 69, no. 10, pp. 4348-4357, 2016.

[15] S. Neamat, "Management Controls For Minimizing Risk In PublicPrivate Partnerships In Kurdistan Region Of Iraq."

[16] T. Krishnan and H. Scullion, "Talent management and dynamic view of talent in small and medium enterprises," Hum. Resour. Manag. Rev., vol. 27, no. 3, pp. 431-441, 2017.

[17] S. D. S. Neamat, "A Comparative Study of Safety Leading and Lagging Indicators Measuring Project Safety Performance," Adv Sci Technol Eng Syst J, vol. 4, no. 6, pp. 306-312, 2019.

[18] O. Furrer, B. S.-C. Liu, and D. Sudharshan, "The relationships between culture and service quality perceptions: Basis for cross-cultural market segmentation and resource allocation," J. Serv. Res., vol. 2, no. 4, pp. 355-371, 2000

[19] Y.-M. Huang, C.-C. Chen, and S.-Y. Lai, "Test of a multidimensional model linking applicant work experience and recruiters' inferences about applicant competencies," Int. J. Hum. Resour. Manag., vol. 24, no. 19, pp. 3613-3629, 2013.

[20] A. Al Ariss and Y. Sidani, "Comparative international human resource management: Future research directions," Hum. Resour. Manag. Rev., vol. 26, no. 4, pp. 352-358, 2016.

[21] W. A. Schiemann, "From talent management to talent optimization," J. World Bus., vol. 49, no. 2, pp. 281-288, 2014.

[22] M. Sonnenberg, V. van Zijderveld, and M. Brinks, "The role of talentperception incongruence in effective talent management," J. World Bus., vol. 49, no. 2, pp. 272-280, 2014.

[23] A. D. Meyer and J. B. Goes, "Organizational assimilation of innovations: A multilevel contextual analysis," Acad. Manage. J., vol. 31, no. 4, pp. 897-923, 1988. 